\title{
Seasonal specialisation in floral resource use by honeybee colonies reveals periods of food shortage in a diverse horticultural and agricultural landscape.
}

\author{
Abigail Lowe ${ }^{1}$, Laura Jones ${ }^{1}$, Georgina Brennan ${ }^{2}$, Simon Creer $^{3}$, Lynda Christie ${ }^{1}$, and \\ Natasha de Vere $^{4}$ \\ ${ }^{1}$ National Botanic Garden of Wales \\ ${ }^{2}$ Institute of Marine Sciences \\ ${ }^{3}$ Bangor University \\ ${ }^{4}$ University of Copenhagen
}

February 4, 2022

\begin{abstract}
Availability of suitable nectar and pollen resources is a limiting factor for pollinator survival, with both overall resource quantity and quality, along with provision throughout the season, being critical. Yet, our understanding of how the selection of floral resources changes over time, and how this relates to floral availability within the landscape is limited. To fill this knowledge gap, we characterise floral use by honeybee (Apis mellifera) colonies, in a diverse horticultural and agricultural landscape, from April to September, over two years, using pollen DNA metabarcoding of honey samples. We compared the pollen found to the availability of host plants within the surrounding landscape using floral surveys. Honeybees used a total of 143 plant taxa, but only 10 of these were determined as major sources ( $>10 \%$ of total sequence reads in any month) and total plant use represented a small proportion of the available floral resources (23\% of genera). Distinct patterns of diet specialisation were identified in June and August, where colonies diverged in their floral preferences before re-aligning in July and September. Following optimal foraging theory, these patterns represent periods of resource limitation. Honeybees showed a preference for flowering trees in the spring, followed by shrubs and herbs in summer and used native and near-native plants more than horticultural plants, as major food sources. DNA metabarcoding allows an increased ecological insight into floral resource use by honeybees and highlights the importance of providing continuous and sufficient floral resources throughout the year.
\end{abstract}

\section{Hosted file}

Honey_MolEcol_MS_28-01-22.docx available at https://authorea.com/users/457931/articles/ 555345-seasonal-specialisation-in-floral-resource-use-by-honeybee-colonies-revealsperiods-of-food-shortage-in-a-diverse-horticultural-and-agricultural-landscape 